important, even crucial, advance may well have been studying chicken-pox and not cancer at all.

\section{REFERENCES}

Ahlström, C. G., and Jonsson, N. (1962). Acta path. microbiol. scand., 54, 145 .

Allison, A. C., and Lightbown, J. W. (1961). Nature (Lond.), 189, 892. Andrewes, C. H. (1939). Proc. roy. Soc. Med., 33, 84.

Dulbecco, R. (1961). Cancer Res., 21, 975.

Furth, J, Yokoro, K., and Takemoto, H. (1962). Ciba Foundation Symposium on Tumour Viruses of Murine Origin, p. 138. Churchill, London.
Habel, K. (1961). Proc. Soc. exp. Biol. (N.Y.), 106, 722.

Hanafusa, H., Hanafusa, T., and Rubin, H. (1963). Proc. nat. Acad. Sci. (Wash.), 49, 572

Huebner, R. J., Rowe, W. P., Turner, H. C., and Lane, W. T. (1963). Ibid, $50,379$.

Kidd, J. G., and Rous, P. (1938). 7. exp. Med., 68, 529.

Koprowski, H., Ponten, J. A., Jensen, F., Ravdin, R. G., Moorhead, P. and Saksela, E. (1962). Ұ. cell. comp. Physiol., 59, 281.

Miller, J. F. A. P. (1962). Ciba Foundation Symposium on Tumour Viruses of Murine Origin, p. 262. Churchill, London.

Munroe, J. S., and Windle, W. F. (1963). Science, 140, 1415.

Noyes, W. F. (1959). 7. exp. Med., 109, 423.

Rogers, S, and Rous, P. (1951). Ibid., 93, 459.

Rubin, H. (1961). Virology, 13, 200.

Rubin, and Vogt, P. K. (1962). Ibid., 17, 184.

\title{
Pyogenic Meningitis in Infancy and Childhood
}

\author{
J. B. HEYCOCK,* M.C., T.D., M.R.C.P., D.C.H. ; T. C. NOBLE, $†$ M.B., M.R.C.P.ED., D.C.H.
}

Brit. med. F., 1964, 1, 658-662

This is a study of all the cases of pyogenic meningitis which have occurred in newborn babies, infants, and children up to the age of 12 years in the Sunderland hospital area during the 13year period 1950-62 inclusive. In this time 337 cases were admitted from a total population of about 400,000. The majority of the cases were treated in Sunderland Children's Hospital and a few at Sunderland Infectious Diseases Hospital. We believe that few, if any, were admitted to hospitals outside this area.

We made this investigation in order to assess the results of treatment over the years, to note if there has been any change in the incidence of bacterial types of meningitis, and to work out a basic plan of management for the future.

Cases have been classified into six groups, depending on bacteriological and clinical findings, and one neonatal group, as follows :

Group 1. Bacteriologically proved meningococcal meningitis.

Group 2. Purulent meningitis. No organism isolated. Petechial rash present.

Group 3. Purulent meningitis. No organisms isolated. No petechial rash.

Group 4. Bacteriologically proved Haemophilus influenzae meningitis.

Group 5. Bacteriologically proved pneumococcal meningitis.

Group 6. Miscellaneous purulent meningitis (1 staphylococcal, 1 streptococcal, 1 salmonella).

Group 7. Neonatal meningitis, with symptoms appearing within 28 days of birth.

\section{Detailed Analysis of the 337 Cases}

The number of cases in each group and the mortality are shown in Table I. There was no significant sex difference in any group.

TABLE I.-Total Numbers and Mortality by Groups

\begin{tabular}{c|c|c|c}
\hline Group & Total No. & Deaths & $\%$ Mortality \\
\hline 1 & 125 & 2 & 1.6 \\
2 & 50 & 4 & 8.0 \\
3 & 100 & 5 & 5.0 \\
4 & 21 & 4 & 19.0 \\
5 & 3 & 6 & 28.6 \\
6 & 17 & 7 & 41.2 \\
7 & 337 & 29 & 8.6 \\
\hline Total & & 22 & 6.9 \\
\hline
\end{tabular}

Table II shows that roughly three out of four cases in any group were under the age of 2 years.

\begin{tabular}{|c|c|c|c|c|c|c|c|}
\hline Age & $\underset{1}{\text { Group }}$ & $\underset{2}{\text { Group }}$ & $\underset{3}{\text { Group }}$ & $\underset{4}{\text { Group }}$ & $\underset{5}{\text { Group }}$ & $\underset{6}{\text { Group }}$ & Total \\
\hline $\begin{array}{l}1 \text { month to }<2 \text { years } \\
2 \text { years and over }\end{array}$ & $\begin{array}{r}100 \\
25\end{array}$ & $\begin{array}{l}40 \\
10\end{array}$ & $\begin{array}{l}74 \\
26\end{array}$ & $\begin{array}{r}17 \\
4\end{array}$ & $\begin{array}{r}19 \\
2\end{array}$ & $\begin{array}{l}2 \\
1\end{array}$ & $\begin{array}{r}252 \\
68\end{array}$ \\
\hline
\end{tabular}

In the tables that follow we have omitted group 6 because of the small number of cases it contains, and group 7, neonatal meningitis, is analysed separately.

There seems to be a significant increase in the number of meningococcal infections during the winter months (Table III), when respiratory infections are at their height (Heycock and Noble, 1962). This trend was absent in the other groups.

TABLE III.-Seasonal Incidence. Number of Cases in Each Month
\begin{tabular}{c|r|r|r|r|r|r|r|r|r|r|r|r}
\hline Group & Jan. & Feb. & Mar. & Apr. & May & June & July & Aug. & Sept. & Oct. & Nov. & Dec. \\
\hline 1 & 20 & 16 & 11 & 17 & 9 & 10 & 4 & 4 & 6 & 8 & 9 & 11 \\
2 & 6 & 4 & 3 & 3 & 5 & 8 & 5 & 3 & 2 & 3 & 5 & 3 \\
3 & 11 & 10 & 8 & 6 & 12 & 4 & 12 & 6 & 5 & 3 & 9 & 14 \\
4 & 3 & 4 & 0 & 2 & 1 & 2 & 2 & 0 & 1 & 2 & 2 & 2 \\
5 & 4 & 2 & 0 & 2 & 3 & 2 & 1 & 0 & 3 & 0 & 4 & 0 \\
\hline Totals & 44 & 36 & 22 & 30 & 30 & 26 & 24 & 13 & 17 & 16 & 29 & 30 \\
\hline
\end{tabular}

We sought the yearly incidence of different types of bacterial infection (Table IV) because it has been suggested that there

TABLE IV.-Incidence of Different Types of Bacterial Infection by Years

\begin{tabular}{|c|c|c|c|c|c|}
\hline Year & Group 1 & Group 2 & Group 3 & Group 4 & Group 5 \\
\hline $\begin{array}{ll}1950 & \ldots \\
1951 & \ldots \\
1952 & \ldots \\
1953 & \ldots \\
1954 & \ldots \\
1955 & \ldots \\
1956 & \ldots \\
1957 & \ldots \\
1958 & \ldots \\
1960 & \ldots \\
1961 & \ldots \\
1962 & \ldots\end{array}$ & $\begin{array}{r}1 \\
3 \\
13 \\
13 \\
13 \\
17 \\
7 \\
11 \\
13 \\
8 \\
9 \\
10 \\
7\end{array}$ & $\begin{array}{r}0 \\
1 \\
2 \\
7 \\
3 \\
5 \\
1 \\
3 \\
6 \\
7 \\
2 \\
3 \\
10\end{array}$ & $\begin{array}{r}4 \\
8 \\
7 \\
8 \\
12 \\
6 \\
7 \\
6 \\
10 \\
10 \\
8 \\
9 \\
5\end{array}$ & $\begin{array}{l}1 \\
1 \\
0 \\
2 \\
0 \\
0 \\
3 \\
3 \\
2 \\
0 \\
3 \\
3 \\
3\end{array}$ & $\begin{array}{l}1 \\
3 \\
2 \\
6 \\
1 \\
0 \\
1 \\
1 \\
1 \\
2 \\
0 \\
2 \\
1\end{array}$ \\
\hline
\end{tabular}

^ Senior Consultant Paediatrician, Sunderland Hospital Group ; Associate Physician, Children's Department, Royal Victoria Infirmary, Newcastle upon Tyne.

+ Consultant Paediatrician, Sunderland Hospital Group. Now at Newcastle General Hospital. 
has been a trend towards an increase in influenzal meningitis and a decrease in meningococcal meningitis in this country in recent years. Our figures support this contention, but there has also been a relative increase in the number of cases from which it has been impossible to isolate any organism (groups 2 . and 3) ; and this may well have been due to partial treatment of meningococcal infections before hospital admission. Thus this apparent trend may be false.

\section{Clinical Features}

Symptoms.-Detailed analysis of the symptoms showed only minor differences within the groups, but the varied reaction according to whether the child was aged 2 years or under necessitated study in two subdivisions. Under the age of 2 years a triad of fever, vomiting, and irritability occurred in two-thirds of all cases, and drowsiness and fits were each noted in $25 \%$ of the total. Fits were present in one-third of groups 4 and 5 . The irritability was often described by the mother as resentment on the part of the baby to being picked up or nursed, contrary to its usual behaviour. A few observant parents remarked upon stiffness of their babies' necks.

In those aged 2 years or more, fever, vomiting, and irritability were still the predominant symptoms and were noted in half of the cases. Drowsiness was present in half, subjective complaint of headache in one-third, and again there was a hiştory of fits in one-quarter of these older toddlers and children. Squint was described in 15 children, 9 of whom were aged 2 years or more. Approximately half of all cases had had symptoms for more than three days before admission, and one-quarter had been given chemotherapy at home. This last factor was most obvious in group 3, where $50 \%$ had been so treated; this might partly explain the sterile cultures and the low mortality in group 3 (Heycock, 1959).

Signs.-In those under 2 years of age the most useful sign was increased tension in the anterior fontanelle, but this was present in only $50 \%$ of cases. A level fontanelle in a dehydrated baby was thought to be of equal significance. We have always regarded neck-stiffness as an unreliable sign in this age-group, but this was, in fact, noted in half of the cases. Kernig's sign was demonstrated in less than $10 \%$. In those aged 2 years or over the picture was more definite, and neck-stiffness was present in almost every case. Kernig's sign was noted in $50 \%$, but photophobia was rare even in the older children. In both age-groups there were concomitant respiratory infections in half of the cases. Fever was present in variable degree in almost every patient, but age and bacteriological type played little part in its degree.

Cerebrospinal Fluid.-The presence of relatively lower cell counts and protein levels with higher sugar values in groups 2 and 3 (Table V) supported our theory that the sterile cultures in these two groups were in many cases the result of treatment before admission. In approximately one-third of the cases treated in hospital it has been clinically necessary to carry out repeated examinations of the cerebrospinal fluid, and this has given us the opportunity of finding out how long the pleocytosis, increased protein values, and diminished sugar values have persisted. Table VI shows that the abnormalities of the C.S.F. may take a long time to regress. In children who had recovered clinically the persistence of a small number of cells or of a

TABLE V.-C.S.F. on Admission

\begin{tabular}{c|c|c|c|c|c|c}
\hline \multirow{3}{*}{ Group } & \multicolumn{2}{|c|}{$\begin{array}{c}\text { White Blood Cells/ } \\
\text { c.mm. }\end{array}$} & \multicolumn{2}{c|}{$\begin{array}{c}\text { Protein } \\
\text { Mg./100 ml. }\end{array}$} & \multicolumn{2}{c}{$\begin{array}{c}\text { Sugar } \\
\text { Mg./100 ml. }\end{array}$} \\
\cline { 2 - 7 } & $<1,000$ & $\geqslant 1,000$ & $<100$ & $\geqslant 100$ & $<45$ & $\geqslant 45$ \\
\hline 1 & 8 & 117 & 15 & 18 & 25 & 3 \\
2 & 17 & 33 & 24 & 15 & 13 & 22 \\
3 & 36 & 64 & 31 & 19 & 35 & 15 \\
4 & 3 & 18 & 5 & 5 & 5 & 2 \\
5 & 3 & 18 & 3 & 5 & 5 & 0 \\
\hline
\end{tabular}

slight increase in protein did not in itself warrant continued treatment.

Length of Stay in Hospital.-Deaths have been omitted from Table VII, which shows that almost $40 \%$ of all cases left hospital within 10 days of admission, and $80 \%$ within 20 days.

\begin{tabular}{|c|c|c|c|c|c|c|c|c|c|c|}
\hline \multirow{2}{*}{ Group } & & & \multicolumn{3}{|c|}{$\begin{array}{l}\text { Cells } \\
\text { c.mm. }\end{array}$} & \multicolumn{3}{|c|}{$\begin{array}{c}\text { Protein } \\
(\mathrm{Mg} . / 100 \mathrm{ml} .)\end{array}$} & \multicolumn{2}{|c|}{$\underset{(\mathrm{Mg} . / 100 \mathrm{ml} .)}{\text { Sugar }}$} \\
\hline & & & $\begin{array}{c}\text { Nor- } \\
\text { mal }\end{array}$ & $5-50$ & $>50$ & $\begin{array}{c}\text { Nor- } \\
\text { mal }\end{array}$ & $\begin{array}{l}50- \\
100\end{array}$ & $>100$ & $<40$ & $\geqslant 40$ \\
\hline 1\{ & $\begin{array}{l}10 \mathrm{c} \\
21\end{array}$ & $\begin{array}{l}\text { lays } \\
\text {, }\end{array}$ & $\begin{array}{l}5 \\
3\end{array}$ & $\begin{array}{l}24 \\
13\end{array}$ & $\begin{array}{l}5 \\
0\end{array}$ & $\begin{array}{l}16 \\
10\end{array}$ & $\begin{array}{r}17 \\
4\end{array}$ & $\begin{array}{l}2 \\
2\end{array}$ & $\begin{array}{r}13 \\
7\end{array}$ & $\begin{array}{l}8 \\
5\end{array}$ \\
\hline 2 & & ", & $\begin{array}{l}6 \\
1\end{array}$ & 11 & $\begin{array}{l}3 \\
0\end{array}$ & $\begin{array}{r}16 \\
4\end{array}$ & $\begin{array}{l}1 \\
0\end{array}$ & $\begin{array}{l}2 \\
0\end{array}$ & $\begin{array}{l}1 \\
1\end{array}$ & $\begin{array}{r}14 \\
2\end{array}$ \\
\hline\{ & $\begin{array}{l}10 \\
21\end{array}$ & ", & $\begin{array}{l}9 \\
6\end{array}$ & $\begin{array}{l}45 \\
11\end{array}$ & $\begin{array}{l}7 \\
1\end{array}$ & $\begin{array}{l}42 \\
15\end{array}$ & $\begin{array}{r}11 \\
2\end{array}$ & $\begin{array}{l}5 \\
0\end{array}$ & $\begin{array}{l}8 \\
6\end{array}$ & $\begin{array}{r}36 \\
6\end{array}$ \\
\hline\{ & $\begin{array}{l}10 \\
21\end{array}$ & ", & $\begin{array}{l}1 \\
0\end{array}$ & $\begin{array}{l}6 \\
6\end{array}$ & $\begin{array}{l}3 \\
2\end{array}$ & $\begin{array}{l}3 \\
4\end{array}$ & $\begin{array}{l}5 \\
3\end{array}$ & $\begin{array}{l}1 \\
1\end{array}$ & $\begin{array}{l}3 \\
2\end{array}$ & $\begin{array}{l}6 \\
2\end{array}$ \\
\hline 5\{ & $\begin{array}{l}10 \\
21\end{array}$ & ", & $\begin{array}{l}2 \\
3\end{array}$ & $\begin{array}{l}5 \\
4\end{array}$ & $\begin{array}{l}0 \\
1\end{array}$ & $\begin{array}{l}6 \\
4\end{array}$ & $\begin{array}{l}0 \\
4\end{array}$ & $\begin{array}{l}0 \\
0\end{array}$ & $\begin{array}{l}1 \\
1\end{array}$ & $\begin{array}{l}2 \\
4\end{array}$ \\
\hline
\end{tabular}

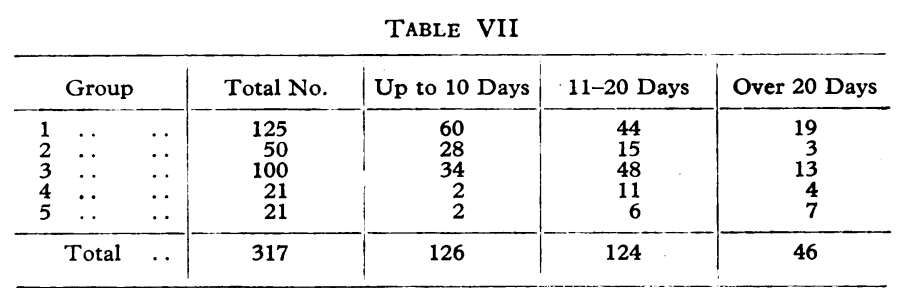

\section{Treatment}

The standard treatment for cases of purulent meningitis on admission to hospital and pending bacteriological identification has been as follows: penicillin, by intramuscular injection, in doses of 500,000 units every.three hours irrespective of age and weight ; sulphadimidine in doses of $0.2 \mathrm{~g}$. $/ \mathrm{lb}$. body weight per day in divided doses every six hours ; and chloramphenicol in doses of $40 \mathrm{mg}$./lb. body weight per day six-hourly. These latter two drugs were given orally in most cases, but occasionally by injection in the early stages of treatment.

This basic treatment was continued until the children were clinically recovered, which in two-thirds of all cases was for a period of about eight days, and was only modified in the following circumstances.

1. Proved meningococcal infections: Penicillin and sulphadimidine continued; chloramphenicol stopped on bacteriological identification.

2. Proved $H$. influenzae infections: Penicillin was stopped and streptomycin in doses of $20 \mathrm{mg}$./lb./day by intramuscular injection was substituted if dictated by bacteriological sensitivity reports. Daily intrathecal injections of streptomycin $25-50 \mathrm{mg}$. were given once daily for four or five days in seven cases. Treatment was prolonged beyond eight days in 11 cases.

3. Proved pneumococcal infections: Penicillin by intrathecal injection of 5,000-10,000 units daily for six or seven days was given in 10 cases. Basic treatment was prolonged beyond eight days in 15 cases.

4. When progress necessitated prolonged use of a broad-spectrum antibiotic, chloramphenicol was often replaced by tetracycline after the first 10 days, because of the risk of aplastic anaemia.

Phenobarbitone was given during the first few days to prevent convulsions. Only 14 patients in the whole series, excepting infants in the neonatal group, were given corticosteroids, and then only where there was evidence of a block developing in the cerebrospinal fluid pathways.

Feeding was usually by clear fluids in the first day or two, but in the rare instances where patients were unable to swallow, short-term intravenous infusions were used.

Every effort was made to reduce high fever by exposure and sponging. 


\section{Follow-up and Complications}

Over $90 \%$ of all cases were seen again after discharge- $-25 \%$ for periods of over a year. The complications are shown in Table VIII. The six subdural effusions occurred in the first seven years of the study. None has been seen in the last six years.

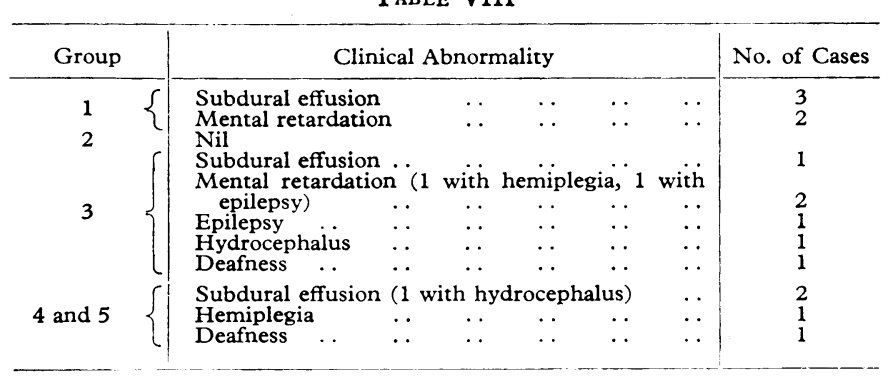

The remaining children appeared to be developing normally, but no formal intelligence tests or audiometric examinations were done. These children were leading a normal life. None of them was regarded as deaf at home or at school, or thought to be suffering from any speech defect. On these rather coarse criteria, therefore, it can be assumed that they had no gross hearing loss.

\section{Neonatal Meningitis}

In this group we have included all babies developing symptoms of meningitis in the first 28 days of life, irrespective of the organisms responsible. There were 17 such patients, of whom only four weighed less than $5 \frac{1}{2} \mathrm{lb}$. $(2,500 \mathrm{~g}$.) at birth. Five had symptoms within 48 hours of birth, five became ill between the third and seventh days of life, and the remaining seven between the eighth and twenty-eighth days.

The duration of symptoms before diagnosis was studied because of the notorious difficulty of diagnosis. Ten cases were diagnosed within two days of the appearance of their first symptoms, five between two and five days from the onset, and there was a delay of more than eight days in the diagnosis of the other two.

\section{Clinical Features}

Symptoms. - The difficulty in diagnosis stemmed from the fact that there was no constancy of symptoms in meningitis at this age. In the 17 cases symptoms were noted with the following frequency: irritability in 10 cases, vomiting in 9, fever in 8, fits in 8, anorexia in 6 , and cyanosis or collapse in 4 . These figures suggested that a lumbar puncture should be considered in any baby of this age-group who had a fit, and that the other symptoms, if persisting and unexplained, should raise the possibility of meningitis.

Signs.-The signs of neonatal meningitis were: temperature above normal in 13 cases, temperature below normal in 4, irritability in 9 , rise in tension of fontanelle in 8 , head retraction in 4 , increased respiratory rate in 3 , cyanosis in 2 , and abdominal distension in 1 . Irritability and fullness of the fontanelle were the only common signs, and even these were absent in almost half of the cases. We have observed one case, and know of two others, in which there was abdominal distension and bilious vomiting, very suggestive of intestinal obstruction.

Cerebrospinal Fluid.-All specimens of cerebrospinal fluid were cloudy or purulent. The results of culture were: coliform organisms in 8 cases, pneumococcus in 2, streptococcus in 1 , paratyphoid $\mathrm{B}$ in 1 , meningococcus in 1 , and no organism in 4 . Despite prolonged treatment the cerebrospinal fluid was very slow to clear, and it was three months before it returned to normal in six of the cases.
Mortality and Morbidity.-There were seven deaths out of 17 cases while under treatment in hospital, and a further two deaths at ages of 1 year and 18 months, both from hydrocephalus. This gave a total mortality of $53 \%$. Among the survivors, four patients appeared perfectly normal three years later. Three others show hydrocephalus (one mild in degree) and one child was microcephalic and severely retarded.

\section{Treatment}

Neonatal meningitis was a difficult and disappointing disease to treat because of the frequency with which interruption of the cerebrospinal-fluid pathways developed, giving rise to hydrocephalus. It thus seemed to us that treatment should be prolonged and should include corticosteroids to try to prevent this sequence of events.

In the cases described we used combinations of the following drugs: (1) Sulphadimidine 0.15 g./lb./day. (2) Chloramphenicol 20-40 mg./lb./day. (3) Streptomycin $20 \mathrm{mg} . / \mathrm{lb} . /$ day. (4) Tetracycline $10 \mathrm{mg}$./lb./day. (5) Intrathecal streptomycin-in two cases, one having four and one having nine injections of $25 \mathrm{mg}$. daily. (6) Prednisolone-10 mg. daily, in steadily diminishing dosage. The duration of treatment in the 10 surviving cases is shown in Table IX.

TABLE IX.-Duration of Treatment in Surviving Cases of Neonatal Meningitis

\begin{tabular}{|c|c|c|c|c|c|}
\hline Drug & & & Up to 10 Days & 10-20 Days & Over 20 Days \\
\hline $\begin{array}{l}\text { Sulphadimidine } \\
\text { Chloramphenicol } \\
\text { Streptomycin } \quad \ldots \\
\text { Tetracycline } \\
\text { Prednisolone }\end{array}$ & $\begin{array}{l}\cdots \\
\cdots \\
\cdots \\
\cdots\end{array}$ & $\begin{array}{l}\cdots \\
\cdots \\
\cdots \\
\cdots\end{array}$ & $\begin{array}{l}0 \\
2 \\
4 \\
5 \\
1\end{array}$ & $\begin{array}{l}0 \\
4 \\
2 \\
3 \\
6\end{array}$ & $\begin{array}{r}10 \\
4 \\
2 \\
1 \\
1\end{array}$ \\
\hline
\end{tabular}

\section{Discussion}

\section{Meningitis in Infancy and Childhood, Excluding Neonatal Meningitis}

Meningitis is still a relatively common disease and highly dangerous from the point of view of mortality and morbidity. The signs and symptoms are often vague and non-specific in the younger age-groups, but the triad of fever, vomiting, and irritability should always raise the suspicion of meningitis. The commonest expression of irritability in infancy is reluctance to being handled. The frequency of fits in the early stages of the disease is so high that we feel a lumbar puncture is almost mandatory in all babies and young children having a first convulsion. Drowsiness is a valuable symptom, but is less often present.

The most constant signs suggesting the diagnosis in this series were petechial rash, increased tension in the anterior fontanelle, and resentment of handling in the infant, and neckstiffness in the older child.

On the patient's arrival in hospital diagnosis is confirmed by lumbar puncture, and immediate examination of the cerebrospinal fluid for cells, protein level, and sugar content ; a stained film is examined microscopically for organisms and a provisional bacteriological diagnosis may be possible immediately, but in every case a culture must be set up as well. In most cases the fluid is turbid owing to the presence of many cells, the protein content is raised, and the sugar is diminished. However, in 12 of our cases admitted early in the disease the C.S.F. was completely normal on the first examination but purulent at a second lumbar puncture within 12 hours. This emphasizes that where the symptoms and signs suggest meningitis a single examination of the C.S.F. is insufficient to deny the possibility of the disease. 
In this series there were a large number of cases from whose C.S.F. no organisms could be cultured, and it is significant that at least half of this group were known to have had sulphonamides or antibiotics in appreciable quantities before admission.

We were surprised at the discrepancy in time between clinical cure and return of the C.S.F. to normal. We feel that treatment should be continued only until the patient is clinically well and the C.S.F. is approaching normal. It was the exception rather than the rule for the C.S.F.s examined more than once to be normal by 21 days.

As regards treatment, we feel that large doses of sulphonamide and antibiotics should be given in combination, and that the initial choice of therapy should cover the possible presence of meningococci, $H$. influenzae, and pneumococci-the three commonest organisms causing meningitis in this country. Sulphadimidine appears to be as effective as, and much less toxic than, any other sulphonamide. We now regularly give phenobarbitone to every case in the first two or three days to try to prevent convulsions, though paraldehyde is the drug of choice for those children actually having fits.

Through the years we have used less intrathecal therapy, partly because large doses of intramuscular penicillin given every three hours appear to penetrate the inflamed theca in adequate concentrations, and partly because we have had a few cases where lumbar punctures, repeated at intervals to introduce penicillin, have resulted in disastrous pressure cones proved at necropsy. This form of management has become safer since other thecal-passing drugs such as chloramphenicol and tetracycline have become available (Esrachowitz, 1961).

Our basic treatment, therefore, is to give half a million units of penicillin three-hourly by intramuscular injection, sulphadimidine 0.2 g./lb. body weight per day, and chloramphenicol in a dose of $40 \mathrm{mg}$./1b./day. These drugs are continued for at least eight days if no organism is cultured.

In meningococcal infections the chloramphenicol is withdrawn on bacteriological confirmation, but penicillin and sulphadimidine are both continued because we feel that the double treatment is justified by the rapid improvement, low mortality, and infrequency of complications.

In proved $H$. influenzae infections we start with the basic treatment but may give intramuscular streptomycin instead of penicillin if the sensitivity tests so indicate (Shaw and Bruyn, 1960).

Cases of proved pneumococcal meningitis are given the basic treatment, and intrathecal penicillin in doses of 10,000 units daily may be necessary.

We have abandoned routine intrathecal antibiotic therapy because we obtain satisfactory results without its use, and because we feel that repeated lumbar punctures may be harmful insomuch that they may be responsible for the formation of subdural effusions through shift of intracranial contents tearing small blood-vessels, and also because of the very real risk of producing medullary pressure cones.

Treatment is continued until clinical recovery is complete, which can be expected to be within eight days in two-thirds of all cases. Only $H$. influenzae and pneumococcal infections commonly require longer treatment.

Clear fluids are given by mouth during the early stages and only occasionally are intravenous infusions necessary. Hyperpyrexia is treated by exposure and tepid sponging. We have not, so far, used artificial hibernation (Veghelyi, 1962).

With regard to aetiology, it would seem that the proportion of bacteriological types is changing slightly, with a relative fall in meningococcal infections and a small rise in influenzal cases and in those with sterile cerebrospinal fluids, but, as stated above, this may be a false presumption. Only meningococcal meningitis shows a definite seasonal pattern of incidence, with the peak during the winter months.
In any type of meningitis the clinical course can occasionally be fulminating, with death a few hours after onset despite treatment. Many of the deaths in this series, especially in meningococcal and influenzal infections, have been in this category.

Among complications we see few subdural effusions compared with many reported series, but we rarely have occasion to suspect their presence, and we believe that vigorous and multiple antibiotic therapy prevents their development. The remaining gross complications include mental retardation, epilepsy, and deafness. We do not routinely arrange estimation of I.Q.s to detect fine degrees of intellectual impairment.

\section{Neonatal Meningitis}

Neonatal meningitis is probably the most difficult clinical picture to describe in the newborn baby because meningitis can present in so many indeterminate ways (B.M.f., 1961). One must suspect this diagnosis in any infant who has a convulsion, shows signs of persistent cerebral irritation, vomits repeatedly, has fluctuations of temperature above or below normal, or has a sudden collapse. Occasionally meningitis in this age-group can cause abdominal distension with bilious vomiting closely resembling intestinal obstruction. It seems to us that there are no characteristic signs and that the tension of the anterior fontanelle is a poor guide. The only way to make the diagnosis is to carry out a lumbar puncture on suspicion.

The results in this group are disappointing, and our future policy will be to use appropriate drugs in a higher dosage than we have done in the past, for a very prolonged period; and, because of the almost inevitable interference with circulation of the C.S.F., to use corticosteroids in every case.

Depending on the organism cultured, we would give the same doses of antibiotics in relation to body weight as we use for meningitis in older children. Coliform organisms are commonest, and here we suggest sulphadimidine for two to three months, chloramphenicol for two weeks or more, and prednisolone in doses of 5-10 mg. each day for the first week, diminishing the dose slowly for a period of up to two months. Intramuscular "colomycin" has been used with encouraging results since this series was completed. The arguments against intrathecal therapy are the same as those in older children.

There is a significantly high incidence of difficult and premature delivery in the mothers of these infants.

In conclusion, meningitis remains one of the few lethal infectious diseases, but a relatively simple plan of treatment almost without intrathecal therapy can reduce the overall mortality to $6.9 \%$, excluding neonates. Partial treatment of meningitis before admission to hospital is increasingly common, and may make the diagnosis more difficult, but does not seem to make the prognosis any worse; however, the chances of finding the causative organism in these partially treated cases are greatly diminished, and this can complicate the treatment in hospital.

The basic need is for constant awareness of the possibility of meningitis, and the confirmation by lumbar puncture without delay.

\section{Summary}

A review is given of 337 consecutive cases of pyogenic meningitis in infancy and childhood, in an industrial area, over a 13-year period.

These cases have been divided into six bacteriological groups and one neonatal group. Separate statistics for mortality and morbidity are given in each group. The overall mortality was $6.9 \%$, excluding the neonatal group, in which the mortality was $41.2 \%$.

A winter peak of incidence was noted in meningococcal meningitis but not in any other group. There has been a slight 
change in the relative incidence of meningococcal and influenzal infections during the period of the survey.

Presenting symptoms and signs are discussed, and the frequency of the combination of fever, irritability, and vomiting is noted. The high incidence of fits is stressed. Cerebrospinal fluid abnormalities are discussed.

A basic plan of treatment has been evolved, with modifications according to the bacteriological findings.

All of these points are considered separately for neonatal meningitis and the diagnostic difficulties are discussed.
We would like to acknowledge the contribution of the medical and nursing staffs of Sunderland Children's Hospital and the Havelock Infectious Diseases Hospital, Sunderland, in the care of these cases. We thank Mrs. B. D. Eldridge for secretarial assistance.

\section{REFERENCES}

Brit. med. 7., 1961, 2, 226.

Esrachowitz, S. R. (1961). S. Afr. med. 7., 35, 281.

Heycock, J. B. (1959). Brit. med. f., 1, 629.

- and Noble, T. C. (1962). Ibid., 2, 879

Shaw, E. B., and Bruyn, H. B. (1960), 7. Pediat., 56, 253.

Veghelyi, P. V. (1962). Ibid., 60, 122.

\title{
Adrenocortical Function in Chronic Malnutrition
}

\author{
J. N. C. COOKE, ${ }^{*}$ † O.B.E., M.D., M.R.C.P. ; V. H. T. JAMES, † PH.D. \\ J. LANDON,§ M.B. ; V. WYNN,§ M.D.
}

Brit. med. F., 1964, 1, 662-666

On clinical grounds there may be difficulty in differentiating a variety of chronic wasting diseases from Addison's disease or hypopituitarism. The differential diagnosis is made more difficult by the finding that in chronic maltnutrition, as in pituitary or adrenal hypofunction, there may be hyponatraemia, an impaired ability to excrete a water load, and undue insulin sensitivity and hypoglycaemic unresponsiveness (Emanuel, 1956 ; Shuster, 1957 ; Nabarro et al., 1957). The urinary excretion of steroids by debilitated subjects may be decreased (Prunty, 1956 ; Bliss and Migeon, 1957) and their response to corticotrophin (A.C.T.H.) may be impaired (Birke et al., 1960), which suggests that all these effects are due to direct or indirect impairment of adrenal function.

The present investigation concerns the effects of chronic malnutrition upon the pituitary adrenal axis and attempts to elucidate some of the mechanisms involved. A further object of the study was to test the validity of using convalescenthospital patients as a control group by comparing their results with those obtained in healthy volunteers.

\section{Material}

A total of 129 adult subjects (61 men and 68 women) were studied. They were divided into three groups in each sex categorized as follows:

Group 1.-This comprised 35 male and 33 female healthy volunteers who were normally nourished and who had had no recent illness or operation.

Group 2.-This comprised 11 male and 17 female hospital in-patients under investigation, or convalescent after various illnesses. They were of near average weight and in no case was this more than $10 \%$ below the expected average for their sex, height, and age. It was considered that these patients would probably correspond to those used as control subjects by most previous investigators.

Group 3.-This comprised 15 male and 18 female patients who were severely wasted owing to a variety of chronic illnesses, and who were under investigation and treatment in a metabolic ward. Their body weights ranged from 20 to $40 \%$ below the expected average

$\star$ Royal Air Force Hospital, Wroughton, Wilts.

t Now at Royal Air Force Hospital, Aden.

\$ Department of Chemical Pathology, St. Mary's Hospital Medical School London.

$\checkmark$ Surgical Unit, St. Mary's Hospital, London. for their sex, height, and age. Of the 33 patients, 11 had panmalabsorption due to a variety of causes, 4 had ulcerative colitis, 6 had rheumatoid arthropathy, 6 had anorexia nervosa, 3 had chronic tubercle involving lungs or bone, 2 had carcinoma, and 1 had a benign oesophageal stricture. None of these patients suffered from an acute infection or had had a recent surgical operation at the time of study. No patient had known endocrine disease or significant reduction in renal function, or had been receiving glucocorticoids.

Because of difficulties in admitting group 1 subjects to hospital our data are incomplete for this group.

\section{Methods}

The following tests were carried out:

1. Estimation of the 24-hour resting urinary excretion of 17-ketosteroids (17-KS) and 17-hydroxycorticosteroids (17OHCS). Wherever possible a minimum of two 24-hour urine collections were obtained and preserved under toluene $(10 \mathrm{ml}$.) at $4^{\circ} \mathrm{C}$. Urinary $17-\mathrm{KS}$ were estimated by the method of Drekter et al. (1952) and 17-OHCS as described by Appleby et al. (1955) modified to include periodate oxidation (Few, 1961). In both methods the colorimetry was modified by the use of ether extraction (James and de Jong, 1961).

2. Measurement of the response of urinary steroid excretion to the intramuscular injection of A.C.T.H. gel (" acthar") 60 i.u. 12-hourly for three days.

3. The determination of the resting plasma-cortisol level in blood samples taken between 9.30 and 10.30 a.m. The plasma cortisol was determined fluorometrically by the method of de Moor et al. (1960) modified as described by James et al. (1962).

4. The plasma-cortisol response to insulin-induced hypoglycaemia (Landon et al., 1963).

5. The determination of the half-life of exogenous cortisol by the method of Brown et al. (1954).

\section{Results}

\section{Urinary Steroid Excretion}

Table 1 compares the mean 24-hour urinary excretion of $17-\mathrm{KS}$ and 17-OHCS in the three different groups of male and female subjects. 